\title{
Información con base en evidencias, cuadros didácticos y marcadores clínicos en mieloma múltiple
}

\section{Information based on evidence, didactic charts and clinical markers in multiple myeloma}

José L. García-Vigil*

Facultad de Medicina, Universidad Nacional Autónoma de México, Ciudad de México, México

Soy médico especialista en medicina interna con alguna experiencia en mieloma múltiple, padecimiento hematológico que diagnostiqué por primera vez durante mi práctica de servicio social en una auxiliar de enfermería, trabajadora de la misma clínica de campo sitio "Ángel Flores", del Instituto Mexicano del Seguro Social (IMSS) en Sinaloa, en donde ejercí mi pasantía en 1974. Ella padecía dolor bajo de espalda de al menos cinco años de evolución, que se agravó durante ese año, por lo que fue necesario incapacitarla y hacerle estudios para valorar su padecimiento. El diagnóstico de presunción, corroborado después por el hematólogo del hospital T1 del Instituto Mexicano del Seguro Social de Culiacán, fue de mieloma múltiple, en virtud de los datos de laboratorio generales (anemia normocítica normocrómica y proteinuria; y por radiografía una gran lesión lítica en dorsales 11 y 12 y 1 y 2 lumbares). En ese momento no tenía compromiso medular ni radicular, lo que me sorprendió debido a la gran lesión lítica.

Esto lo recordé al leer el trabajo, exhaustivo y completo, del consenso de expertos mexicanos que acordaron plasmar en el texto las evidencias disponibles de su investigación documental sobre dicho padecimiento. Celebro la organización de la información en nueve módulos con base en evidencias, cuadros didácticos con marcadores clínicos, de imagen y pruebas especiales (cadenas ligeras, médula ósea, tinciones histológicas específicas); además de estadios con pronóstico y tratamientos según el caso. Esta información sobre mieloma múltiple será auxiliar de apoyo para establecimiento del diagnóstico básico y diferencial para médicos generales, hematólogos y especialistas generales. 